\title{
Digital transformation of SME business models as a factor of sustainable socio-economic development
}

\author{
Tatiana Sinyuk*, Elena Panfilova and Ruzanna Pogosyan \\ Rostov State University of Economics, 344019 Rostov-on-Don, Russia Federation
}

\begin{abstract}
The article deals with technological and managerial aspects of digital transformation of Russian SME business models. The purpose of this article is to develop theoretical and practical approaches to the study of SME business models based on the index of digital transformation of Russian SMEs to justify effective policies for sustainable socio-economic development of the regional and national economy. The article provides quantitative estimates of various parameters of SME business models digitalization using the index of digitalization for SMEs, and also notes the uneven digital development of SME business models in the structural aspect of the array of economic actors, as well as for different sectors of the economy and indicates the existing differences in "digital maturity" business models between SMEs of the capital and regional SMEs. The differences and specific features between different types of business models of SMEs depending on their degree of digital maturity are noted.
\end{abstract}

\section{Introduction}

Topicality of the research topic is determined by the fact that the COVID-19 pandemic has posed new digital challenges for SMEs, reinforcing the leading trend of automating business models of business entities as a critical factor in sustainable socio-economic development. During the 2020 pandemic, global Internet use increased by $50-70 \%$ [1]. At the same time, this growth occurred unevenly across countries, industries, groups of economic actors and with different risks [2].

Digital transformation helps businesses to overcome the "economic distance", reflecting the natural and necessary alternative to organize the interaction of SME business processes [3]. At the same time, the high speed of digitalization of business processes carries with it certain threats and risks of automation of entire spheres of the economy [4]. Even before the pandemic, some forecasts indicated that digitalization in the service industry by 2035 would result in up to $86 \%$ of restaurant jobs, up to $75 \%$ of retail jobs, and $59 \%$ of entertainment and hospitality jobs being fully automated [5].

In other words, the digital transformation of the external business environment and internal business processes of SME enterprises as a factor of sustainable socio-economic

\footnotetext{
*Corresponding author: $\underline{\text { t_sinyuk@ mail.ru }}$
} 
development, emerged even before the pandemic, and in modern conditions is amplified and disclosed by a new spectrum of its specifics and risks.

From this perspective, the sustainability and competitiveness of the entrepreneurial potential of SMEs is determined not only by the quality of goods and services provided, but also by the quality of digitalization of the business models of these entities.

However, it should be noted that for different types of SMEs, digital transformation means different levels of implementation of technological and managerial aspects of business models aimed at improving the efficiency of interaction of SMEs with their suppliers, customers and partners and state regulators [6]. All this is realized in different types of organization of external and internal business processes of the enterprise (the first type of SME business model "first business, then technology" and the second type of SME business model "first technology, then business").

In addition, the processes of digital transformation of SMEs occur unevenly, both for different types of business entities, and in the regional and national context, which imposes certain specifics on the course of the processes of SME business processes digitalization.

In the scientific literature, there is a large body of articles devoted to the digitalization of SMEs in various aspects: digitalization of people (Artificial intelligence, AI); digitalization of things (Internet of Things, IoT); digitalization of reality (Augmented reality, AR); digitalization of logistics (Blockchain, IB). All this contributed to an active scientific search for models of digital maturity of enterprises and the assessment of digital maturity according to a variety of criteria, indices and indicators [7-10].

The coverage of digitalization of SMEs covers a wide range of problems: the development of CRM-systems for SMEs [11], consideration of IT-technologies as a factor in enhancing the competitiveness of SMEs [14-15]; formation of management decision support information systems for SME subjects [16-17]; studies of information logistics for SMEs [18], development of digital training and business consulting in SMEs [19-21], etc. At the same time, it should be noted that, in general, the research on digitalization in SMEs is fragmented, reflecting the digital transformation of individual economic entities of SMEs.

In foreign studies, the range of scientific interests in the digital transformation of SMEs is very diverse, but there are no unambiguous evaluative opinions - some researchers believe that digital transformation favorably affects the organization of business models of SMEs [22-23, 13], development of digital maturity assessment models for individual enterprises and sectors of the economyetc [9]. While other researchers raise concerns about the sustainability of the "digital competitive advantage" of SMEs [24-15].

Such diametrical points of view are explained to some extent by the fact that on the one hand - the conceptual framework of digital transformation has not yet been clearly defined [26-27], and on the other hand - such a subject of research as business models of economic entities still refer to a fairly new branch of organizational research [23, 28-29] etc.

It should be noted that the issues of quantitative measurement of managerial and technological aspects of the digitalization of SME business models as a factor in sustainable socio-economic development at both national and regional levels remain understudied [30].

The purpose of this article is to develop theoretical and practical approaches to the study of SME business models based on the index of digital transformation of Russian SMEs to justify effective policies for sustainable socio-economic development of the regional and national economy.

\section{Research methodology}

The research methodology for the digitalization of SME business models is based on monitoring the technological and managerial characteristics of the digital transformation of 
SME functioning within the framework of the digitalization index of small and medium-sized businesses in the Russian Federation. In terms of the technological aspects of digitalization of the interaction of economic entities - the Russian Federation has its advantages. Russia ranks seventh in the world in terms of the number of Internet users, $82 \%$ of the country's population use the Internet, and $71 \%$ of Russian Internet users go online every day (Net, 2020).

National goals for the development of the Russian economy by 2030 include an increase in the share of households with broadband Internet access to $97 \%$, as well as an increase in the share of mass socially significant services available in electronic form to $95 \%$. The number of people employed in small and medium-sized businesses, including individual entrepreneurs and self-employed, should increase to 25 million people. By 2030, "digital maturity" should be achieved for both business entities and key sectors of the national economy [33].

Digital transformation of business models is an economic activity in which digital data is a key factor in production, processing large amounts of data and using the results of analysis, compared to traditional forms of business, can significantly increase efficiency in various fields of activity. types of products, technologies, equipment, storage, sale, delivery of goods and services.

However, despite the significant level of Internet users in Russia, the level of digitalization of business models of enterprises remains insufficiently high. On average, 14 $\%$ of all Russian enterprises have a high level of "digital maturity" and extensive integration of business processes based on IT technologies, $36 \%$ use non-integrated business processes using IT technologies, $46 \%$ use several integrated business processes using IT technology [31].

This is due to the fact, that digitalization processes form two different types of businesses of SME models, for which the use of IT technologies carries different costs and the level of risks to the sustainability and openness of the business.

For those, SMEs that rely on the traditional business paradigm - "first business-processes, and then digital technologies", a cautious and poorly motivated attitude towards digitalization of business processes is characteristic, as this requires additional investment in the development of digital skills of workers, which is associated with the rise in cost, information security and openness of the business platform of the enterprise.

Other SMEs based on the paradigm "digital technologies first, then business processes" have the opposite - they are actively motivated to use information technologies in all business processes, they are ready to build their business online, use various information products, Internet logistics, the Internet - things to improve efficiency interactions with their suppliers, customers and partners.

One of the integrated indicators of "digital maturity" of SME business models can be used index of digitalization of Russian business (BDI), which includes both technological components of digitalization (digital transmission and storage channels, information security) and managerial components of digitalization of business models - Internet use in sales, digital technology integration (CRM), digital learning- Figure 1. 


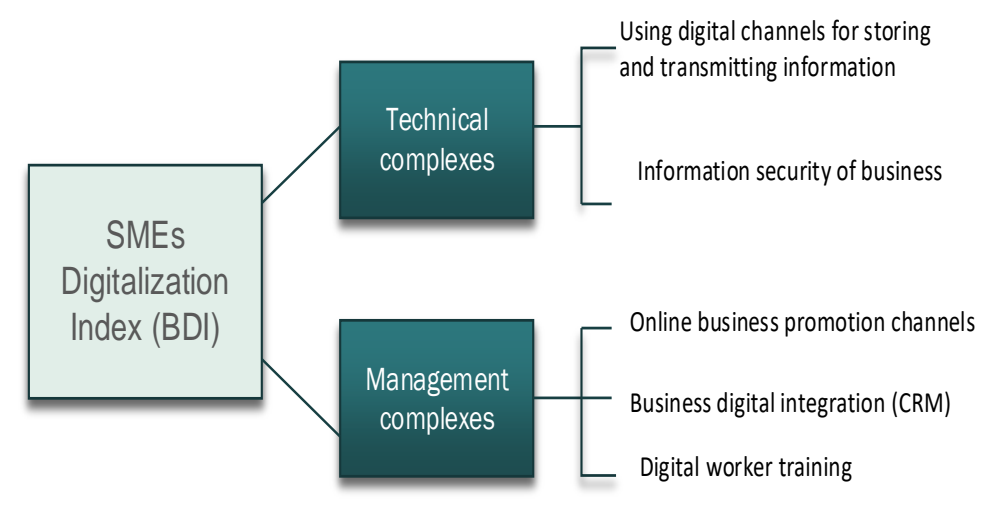

Fig. 1. Technical and management components of the Russian Business Digitalization Index (BDI)

The Business Digitalization Index is the level of readiness of small and medium-sized companies to digitally transform their business environment. The BDI index can take values from 0 percentage points (minimum) to 100 p.p. (maximum) and is calculated as the arithmetic average of the values of the five main components.

Let us consider the technological and managerial aspects of the digitalization of business models of Russian SMEs.

\section{Results of the study}

\subsection{Technological aspects of the digitalization of SME business models}

Monitoring of technological aspects of the process of digitalization of SMEs is conducted in the area of frequency of use of the Internet as a channel of information transfer, availability of own sites of SMEs in social networks, as well as information security of SMEs - Figure 2 [32].

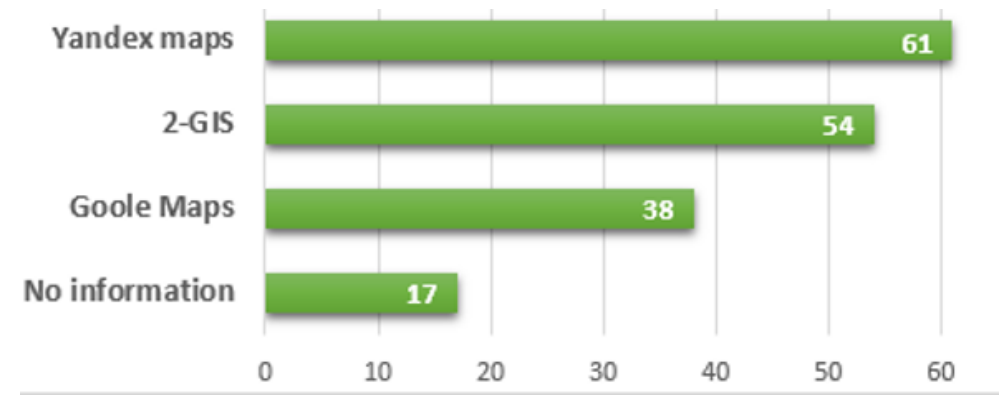

Fig.2. Information sources by Russian SMEs on online maps, 2020 (\%)

As can be seen from Figure 2, only 43\% of SMEs have their own pages on the Internet, information on Internet maps have - Yandex maps - 61\%, 2Gis maps -54\%, Google Maps $38 \%$, no information - 17\%. The most popular social networks among SMEs are in contact $74 \%$, Intagram - 54\%, Facebook -34\%. (Figure 3) [32, 36]. 


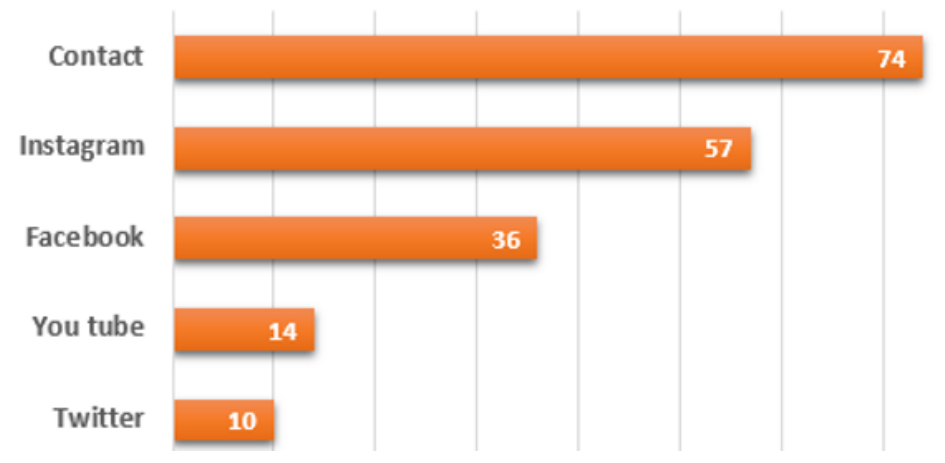

Fig. 3. Use of social media by Russian SMEs,2020 (\%)

Until recently, the information security goals of SMEs were achieved mainly by implementing the principle of "maximum secrecy", according to which access to information about the company was limited, and not always justifiably so.

At the same time, technical protection of commercial information should not contradict the objectives of companies' development in the network, but private commercialization of information protection tools market is perceived by many SMEs as an obstacle to information security and an additional cost item, so $23 \%$ of Russian SMEs do not use any technical means of information protection - Figure $4[32]$.

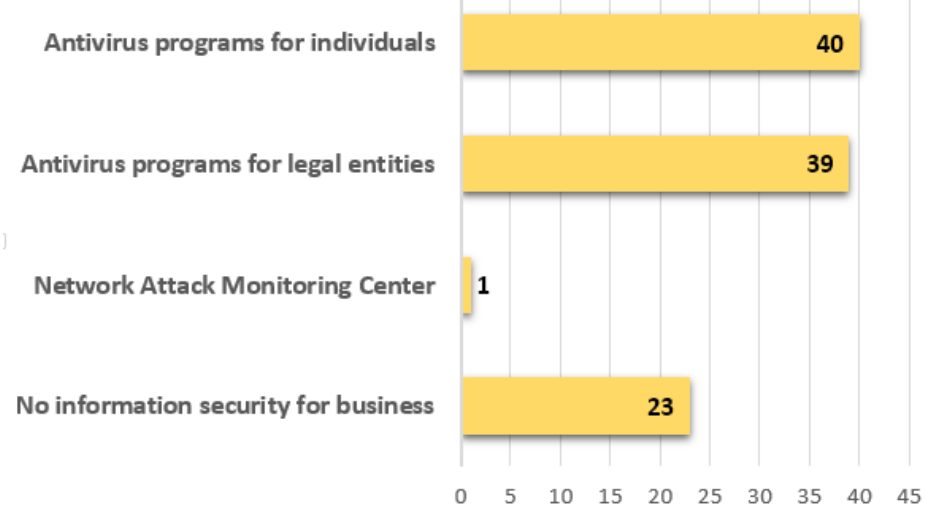

Fig. 4. Information security of the Internet by Russian SMEs, 2020 (\%)

Figure 4 shows, that $40 \%$ of SMEs use antivirus software for individuals, $39 \%$ of SMEs use antivirus software for legal entities, and 1\% of SMEs have a network attack monitoring center. All this confirms the fact that SMEs pay insufficient attention to information security issues.

It should be noted that the technical factors of digitalization of business models of Russian SMEs still remain a significant barrier to the transition to the full integration of SME business processes. Thus, $57 \%$ of Russian SMEs do not have their own page in social networks and the Internet, which indicates an insufficient level of technological use of the Internet as basic channels of information about their companies. 


\subsection{Managerial aspects of the digitalization of SME business models}

The use of the Internet in marketing communications makes it possible to organize an effective business model for SMEs, which ensures not only the stable development of the company, but also increases the efficiency of the enterprise in comparison with other market agents.

Internet technologies act as the main tool for meeting information needs and creating an effective system of relationships between enterprises and consumers, as well as with all elements of the external business environment. However, $30 \%$ of SMEs do not use the market potential of Internet marketing tools - Figure 5 [32].

Figure 5 shows that overall $46 \%$ of SMEs use Internet marketing tools in their business models. Internet marketing tools in their business models. The most popular are: advertising promotion through offline channels - 37\%, e-mail marketing $-26 \%$, placement of ads on trading platforms in Avito, Ozon, eBay - 25\%. Least popular least popular among SMEs are tools for making cold calls through call centers $-9 \%$.

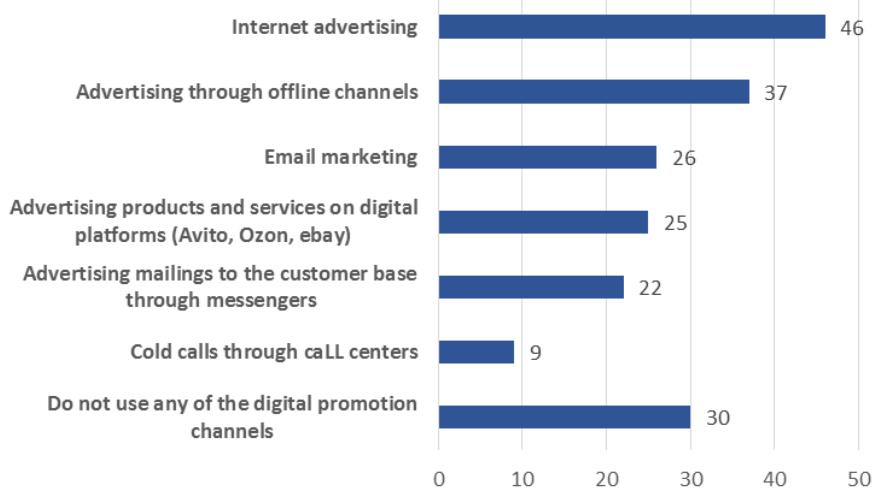

Fig. 5. Use of the Internet in marketing communications by Russian SMEs, 2020 (\%)

Digital competencies are a critical factor in the competitiveness of small and mediumsized enterprises, because the acquisition of digital skills requires new educational technologies and platforms, ensuring the sustainability of the balance of digital, professional and "soft" skills development SMEs on the basis of continuing education -Figure 6 [32].

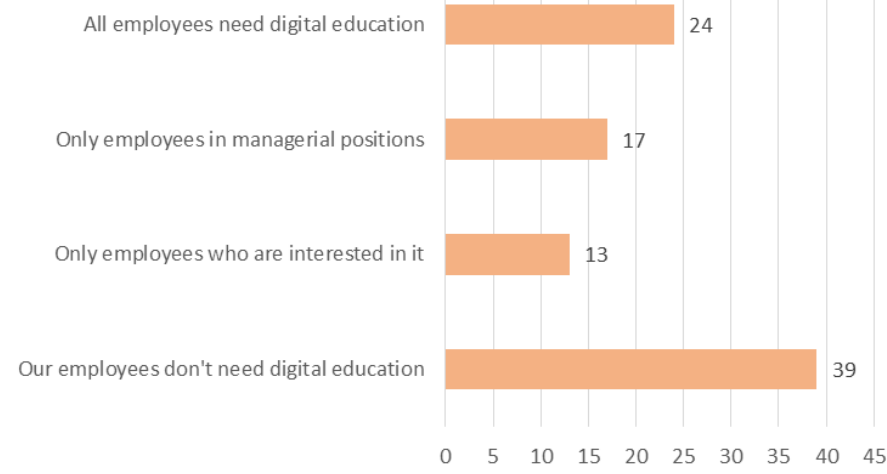

Fig. 6. Digital training for Russian SMEs, 2020 (\%).

As can be seen from Figure 6, a fairly large number of SMEs - 39\% believe that digital training is not necessary for employees of the firm, $13 \%$ believe that it is necessary for those who are interested in it, $17 \%$ of surveyed SMEs believe that digital education is necessary 
for company executives, but not for ordinary employees. In general, training in digital products and services is not yet perceived by SMEs as an urgent and important issue in the development of human resources capacity of their firms. A total of $12 \%$ of companies have their own digital specialists. Specifically, $9 \%$ of companies have internet marketers, $8 \%$ have web analysts, and $7 \%$ have web developers.In $4 \%$ of small and medium-sized companies, all employees work remotely, and $40 \%$ have some employees. In general, training in the use of digital products and services is not yet perceived by Russian SMEs as an urgent and important problem of quality development of human resources potential of their companies.

\section{Discussion of the results}

The controversial aspects of the study are the spatial unevenness of the digitalization of SME business models in the regions of the Russian Federation and the capital region (Moscow) from the standpoint of technologic and managerial aspects of the functioning of business models of this sector of the economy.

In the regional aspect, the readiness to digital transformation of SMEs in Moscow is higher than the on average in the regions of the Russian Federation. For example, the BDI index for Moscow is $41 \%$, and for the Russian Federation $-34 \%$, including due to more active use of internet channels and the integration of information platforms of interaction SMEs with their suppliers and consumers (51\% in Moscow). The most popular intercorporate technology both in Moscow (40\%) and in the regions (39\%) is intranet. Moscow companies implement CRM-systems ( $27 \%$ vs. $15 \%)$, chat-bots (11\% vs. $6 \%)$, and automated solutions for personnel management ( $13 \%$ vs. $5 \%$ ) more often than in the regions.

The main advantages of digitalization of business models of SMEs are: easy control of the business process of the organization (34\%), increasing the speed and efficiency of business - 33\%, improving customer service - $15 \%$, the benefits are, but they are not clear 18\%. Technical and management components Small Business Digitalization Index (BDI) by region and in Moscow, 2020 (percentage points)- Figure 7 [32].

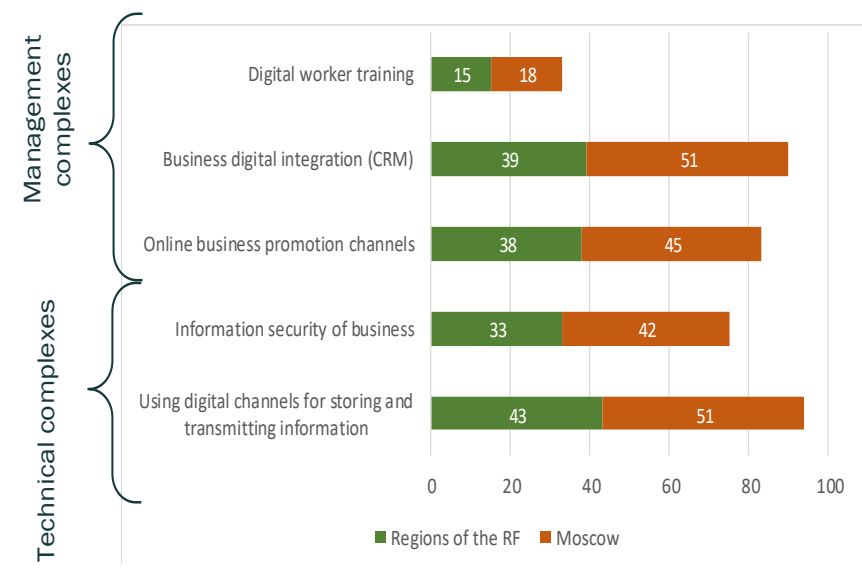

Fig. 7. Technical and management components Small Business Digitalization Index (BDI) by region and in Moscow, 2020 (percentage points)

As can be seen from Figure 7, both for Moscow and regional companies more often than the average for the Russian Federation.

More than half of Moscow companies (57\% vs. $26 \%$ in the regions) have a comprehensive website with detailed information about the company and its activity. Also one third of organizations registered in Moscow (36\% vs. $28 \%$ in the regions) have a social networks. 
Regional breakdown of the main structural components of the small business digitalization index (BDI) in the Russian Federation and Moscow (\%)

Among the main barriers to the processes of digitalization of business by SMEs noted the lack of interest among managers of companies $20 \%$, as well as the lack of as such serious barriers to the implementation of the market potential of digital technology in the development of small and medium-sized businesses (27\%).It is noteworthy that among the barriers to business digitalization, psychological and managerial aspects, related to the lack of interest of managers in the digitalization of business, rather than technical and infrastructural aspects of SMEs' business, came to the fore.rDigital transformation of business models of Russian SMEs by type of enterprise, 2020 (\%), reflected in Table 1

Table 1. Digital transformation of business models of Russian SMEs models of Russian SMEs by type of enterprise, $2020(\%)$

\begin{tabular}{|c|c|c|}
\hline Type of SME & $\begin{array}{c}\text { Business model } \\
\text { with a } \\
\text { low level of } \\
\text { "digital maturity" }\end{array}$ & $\begin{array}{c}\text { Business model } \\
\text { with a high level of } \\
\text { "digital maturity» }\end{array}$ \\
\hline 1)Small business & 83 & 17 \\
\hline 2)Medium business & 80 & 20 \\
\hline 3)Micro enterprises & 93 & 7 \\
\hline $\begin{array}{c}\text { Average for the Russian } \\
\text { Federation }\end{array}$ & 85,3 & 14,6 \\
\hline
\end{tabular}

The maximum gap between metropolitan and regional SMEs falls on the item «Business digital integration» - 12 p.p. in favor of Moscow SMEs, the minimum gap on the item «Digital worker training»- 3 p.p. Both components relate to the managerial aspects of the digitalization of Russian SME business models, which confirms the fact that the gaps in the digital transformation of SME business models are easier to overcome in the technical aspects, while management and digital training require a longer perspective and integration models that can really change the external and internal business processes at the enterprise.

Thus, increasing the level of digital maturity of an enterprise is a complex iterative process that does not have a single development trajectory for different types of SMEs, depending on the sphere of economy, regional space, business model, management and company strategy.

\section{Conclusions}

The Covid-19 pandemic crisis has greatly intensified the digitalization processes of both the external and internal environment of SMEs. SMEs have been hit hardest by the instability and risks of government restrictions, since SMEs are actually under-resourced, which makes them most vulnerable, especially in the services sector.

The digital maturity of an organization consists of both technological and managerial aspects, so different methods, approaches, indicators and criteria for assessing the "digital maturity" of enterprises are used.

Transformation of the business model is one of the most important components of the growth of digital maturity of the enterprise and is carried out in the direction of increasing collaborative interactions, application of multilateral platforms and creation of business ecosystems. This approach has increased enterprise agility as a key factor of enterprise competitiveness in the digital economy.

Thus, despite the growing number of Internet users and the digital transformation of interaction between business entities, two different types of SME business models have emerged for different SMEs. 
The first type of business model is more traditional, based on the concept of "business first, then digital technology", this business model format is characterized by a cautious and little motivated attitude to the digitalization of business processes, as it requires additional investment, new digital skills, which is associated with higher costs, security and business openness. Thus, $57 \%$ of Russian SMEs do not have their own pages on the Internet and social networks, $17 \%$ are not displayed on the online maps, indicating the lack of use of Internet technology as the main channels of information about their companies. Among small businesses, the share of organizations with an insufficiently high level of digital maturity of their business model is $93 \%$ among microenterprises, $83 \%$ among small businesses, and $80 \%$ among medium businesses.

Thanks to the business model of a higher level of digital maturity based on the concept of "digital first, then business", SMEs are actively motivated to use information technology in all business processes; they are willing to build their business online and use various information products to improve effective interaction with their customers, suppliers and partners. Thus, $43 \%$ of Russian SMEs have their pages on the Internet, $46 \%$ of SMEs use Internet marketing tools in their business models, they see the advantage of digitalization of business in what it gives - convenient management of business processes of the organization. (34\%), an increase in the speed and efficiency of business - 33\%, improved customer service - 15\%. Among Russian SMEs, the share of organizations adhering to a high level of digital maturity of business models, microenterprises is $-7 \%$, small businesses - $17 \%$, medium businesses $-20 \%$.

For future research in this area, it should be taken into account that these are two different digital morphotypes of SME business models and they require completely different instruments of state support for the development of entrepreneurial initiative and entrepreneurial potential, including various support measures for the formation of a digital infrastructure for SMEs.

\section{References}

1. M. Ramos, World Economic Forum, https://www.weforum.org/agenda/2020/07/ (2020)

2. IMF COVID-19 Risk Report: Preliminary Comparison and Implications, http://www3.weforum.org/docs/WEF_COVID_19_Risks_Outlook_Special_Edition_Pa ges.pdf (2020)

3. A.A. Shpileva, Economy, Entrepreneurship and Law. 11 (2), 299 (2021)

4. E.V. Erokhina, Yu.B. Dzhergeniya , Economic security, 3(3), 259 (2020)

5. C. B. Frey, M. A. Osborne, Technological Forecasting and Social Change, 114, 254 (2018)

6. S. Ilyashenko, M. Belyakova, A. Zvereva, IOP Conference Series, 940 (2020).

7. D.V. Kuzin, The world of the new economy, 13 (3), 89 (2019)

8. T.A. Gileva Bulletin of USPTU. Science, education, economics, (1 (27)), 38 (2019)

9. , O. A Valdez-de-Leon, Technology Innovation Management Review, 6, 19 (2016)

10. P. Wirkkala, M. Saarela, K. Hanninen, J. Kujala, A. Simunaniemi, Management, 15, 137(2020).

11. I.S. Baranovsky, M.A. Tolkachev, Proceedings of BSTU, Economics and Management. 1 (208), 66 (2018)

12. H. Bauman, S. Nicu, M. de Reuwer, Telecommunications Policy, 43 (9) (2019)

13. J. Bedell-Pearce, Network Security, 6 (2018) 
14. A.Yu. Korablev, R.E. Bobkin, Azimut Scientific Research: Economics and Management. 7 (1), 44, (2018)

15. V.O. Odinev, Transportnoe delo Rossii, 6 (2009)

16. A.N. Tselikh, L.A. Tselikh, Izvestia SFU. Technical Sciences, 11 (148), 232 (2013)

17. E.V. Drobot, I. N. Makarov, S. M. Manasyan, V.S. Nazarenko, V.S. Bakhmutskaya, Creative Economy, 14 (10), 2413 (2020)

18. I.V. Khateev, Vestnik of the South Ural State University, 30, 187 (2012)

19. T.K. Rostovskaya, I.V. Groshev, Y.D. Krasovsky, Digital Sociology, 2, 46 (2019)

20. O.I. Yudin, Value-based approach to the formation of a client-oriented business model of the company $(\mathrm{SPb}, 2014)$

21. A.Z. Zaitseva, Economics, Entrepreneurship and Law, 11(2), 213 (2021)

22. S. Denicolai, A. Zucchella, G. Magnani, Technology Foresight and Social Change, 166 (2021)

23. H. Bouwman, S. Nikou, M. de Reuver, Telecommunications Policy,101828 (2019).

24. I. Zambon, G. Aegidi, F. Rinaldi, S. Cividino, MDPI AG (2019)

25. R. Bongaerts, M. Kwiatkowski, T. Koenig, Disruption Technology in Mobility: Customer Acceptance and Examples (2017).

26. J. Reis, M. Amorim, N. Melão, P. Matos, Trends and Advances in Information Systems and Technologies, 745 (2018)

27. X. Zhang, International Journal of Innovation Studies, 2, 2 (2018)

28. M. Westerlund Review of innovative technology management, 1346 (2020)

29. K. Isensee, F. Teutheberg, K.M. Griese, K. Topi, Journal of Cleaner Production, 1244 (2020)

30. T.Yu. Sinyuk T, E.A. Panfilova, N.N. Yevchenko, R.R. Pogosyan, M.T. Belov, European Proceedings of Social and Behavioural Sciences, 12 (2019)

31. RBC + Information Technology Appendix The pandemic has accelerated the digitalization of business, https://plus.rbc.ru/news/5f8f191f7a8aa930ddd3c51

32. Index of digitalization of small and medium-sized businesses, https: //www.nwab.ru/content/data/store/images/f_576_73187_1.pdf

33. Decree of the President of the Russian Federation. July 21, 2020 No. 474 "On the National Development Goals of the Russian Federation for the period until 2030", http://kremlin.ru/events/president/news/63728

34. The Net as Salvation Analytical review by the All-Russian Center for Public Opinion Research, https://wciom.ru. 